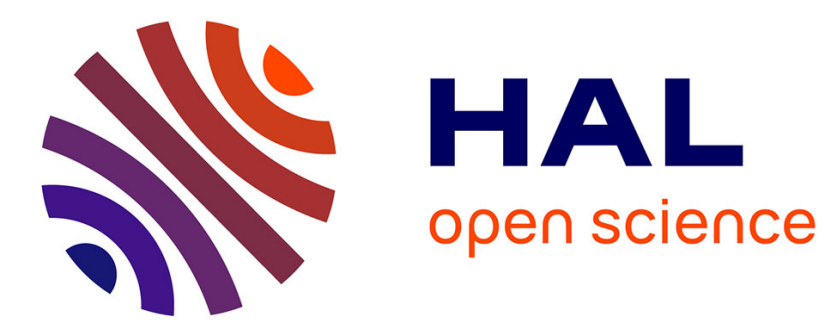

\title{
Non-classical water diffusion in an industrial adhesive
}

Romain Léger, A. Roy, J.-C. Grandidier

\section{To cite this version:}

Romain Léger, A. Roy, J.-C. Grandidier. Non-classical water diffusion in an industrial adhesive. International Journal of Adhesion and Adhesives, 2010, 30 (8), pp.744 - 753. 10.1016/j.ijadhadh.2010.07.008 . hal-01883670

\section{HAL Id: hal-01883670 \\ https://hal.science/hal-01883670}

Submitted on 3 Nov 2020

HAL is a multi-disciplinary open access archive for the deposit and dissemination of scientific research documents, whether they are published or not. The documents may come from teaching and research institutions in France or abroad, or from public or private research centers.
L'archive ouverte pluridisciplinaire HAL, est destinée au dépôt et à la diffusion de documents scientifiques de niveau recherche, publiés ou non, émanant des établissements d'enseignement et de recherche français ou étrangers, des laboratoires publics ou privés. 


\title{
Non-classical water diffusion in an industrial adhesive
}

\author{
R. Leger ${ }^{\mathrm{a}, *}$, A. Roy ${ }^{\mathrm{a}}$, J.C. Grandidier ${ }^{\mathrm{b}}$ \\ ${ }^{a}$ CRITT Matériaux Poitou-Charentes, Rochefort sur Mer, France \\ ' Département de Mécanique et Physique des Matériaux, Institut P' CNRS, Université de Poitiers, ENSMA, UPR 3346, Chasseneuil du Poitou, France
}

\begin{abstract}
A B S T R A C T
Experimental studies were performed on an industrial rubber toughened epoxy adhesive to characterise its diffusion behaviour in water at various temperatures. Gravimetric experiments and density measurements were carried out at $25,40,60$ and $70^{\circ} \mathrm{C}$ on bulk specimens. Non-classical mass uptake and swelling were observed. Differential scanning calorimetry and surface fracture analyses were undertaken to understand this specific behaviour. Experiments showed that adhesive glass transition was crossed during aging, and that cavities developed during sorption. Part of the water diffused in the matrix causing the decrease of the adhesive $T_{\mathrm{g}}$ while the other part entered into cavities. To model the water uptake and swelling of the adhesive, it had been chosen to separate the water mass fraction into two parts. A thermo-diffuso-mechanical modelling based on a thermodynamic framework was proposed to solve the diffusion problem. The model was implemented in a user subroutine for ABAQUSTM and a 2D finite element modelling was designed to obtain the simulated diffusion behaviour of the adhesive. Mass uptake and swelling were simulated for different aging conditions and confronted to experimental results. Although a slight deviation was observed between experimental and modelled swellings at 60 and $70^{\circ} \mathrm{C}$, numerical results were satisfactory at mass uptake at $25,40,60$ and $70^{\circ} \mathrm{C}$ so confirming previous hypotheses.
\end{abstract}

Keywords:

Epoxy/epoxides

Aging

Durability

Microscopy

Finite element modelling

\section{Introduction}

Structural bonding with epoxy adhesive is increasingly being employed in the automotive industry to provide for example the ability to be more resistant in crashes or to lighten vehicle bodies. During its service lifetime a bonded joint will be submitted to environmental loading such as high humidity and/or temperature. Investigations [1,2] show a decrease of the joint strength when immersed into demineralised water. In general this loss of properties is attributed to the degradation of the adhesive or the interface.

To explain the absorption of water by an epoxy adhesive, it has been hypothesized that water equilibrium concentration could be governed by the free volume and the defects of the adhesive. Molecules of water diffuse from a void to another constituting a preferential way of ingression [3]. But this theory is questionable since polymers rich in free volume can have a very low hydrophilicity [4]. For many authors, absorption is more likely to be an attraction of the polar molecules of water into the network by hydrophilic groups of the adhesive such as $-\mathrm{OH}$ or $-\mathrm{NH}$ to form simple hydrogen bonds [5] or more complex associations [6]. The number of these groups determines the water equilibrium concentration (or solubility) of the adhesive.

\footnotetext{
* Corresponding author. Tel./fax: +335494982 39

E-mail address: romain.leger@ensma.fr (R. Leger).
}

But most of the time, a combination of both theories seems to be in good agreement with experimental observations [6,7].

Diffusion of water into the adhesive is responsible for a decrease of its mechanical and physical properties (Young modulus, ultimate stress, $T_{g}$, etc.). These modifications depend on the environmental conditions (temperature, pressure, humidity rate). A reversible plasticization is often observed when water molecules form hydrogen bonds in the network. For short time exposure at low temperature, initial properties are recovered after a drying stage. But for long time immersion and/or high temperature exposure, irreversible reactions can occur like hydrolysis [8], formation of complex chemical groups [9] or cavitation [10]. Such phenomenons will obviously make more complex the diffusion process [4].

The concentration of water in the adhesive is not homogeneous and depends on the time of immersion. A classical Fickian law commonly gives good prediction of the mass uptake of a model epoxy immersed in water $[4,11]$. But for some network or for specific environmental conditions more complicated laws [12], such as a two-phase nature sorption model (dual stage Fickian model) [13], a two-phase moisture sorption model (Langmuir-type model) [14] or time or concentration-dependent diffusivity model $[15,16]$ give better prediction.

In the literature concerning the diffusion of water, in most cases adhesives are model epoxies filler free or with perfectly known and controlled composition. In addition, since the 
plasticization generated by water ingression is responsible for a decrease of $T_{g}$ [17], gravimetric studies are carried out in the glassy state of the adhesive, i.e. at aging temperature well below $T_{g}$. An adhesive with industrial composition (i.e. with heterogeneous composition: various epoxy mixture, inorganic fillers, rubber fillers, accelerators, plasticizers, etc.) can have a nonclassical behaviour in terms of water diffusion [13], the glass transition temperature of the epoxy/water complex can be crossed [4] during the aging, and damage can occur, making even more complex the study of its behaviour. Those phenomenons can obviously depend on temperature. The present work consists in developing a model that can describe a non-classical diffusion of water in an industrial adhesive as a function of temperature and the formation of cavities. The second part of this article is dedicated to the presentation of the bulk adhesive and the manufacture of specimens. In a third section, experimental results concerning water diffusion in the adhesive as a function of temperature and characterisation of the adhesive as a function of water uptake are presented and the origin of the non-classical uptake is discussed. In a fourth part, previous experiments are considered to develop a water diffusion model which is based on classical thermodynamics where a non-conventional way to describe solubility is also proposed. Ensuing transport equations are solved with engineering finite elements code ABAQUS ${ }^{\mathrm{TM}}$. Specific numerical developments are necessary and are presented in this section. Finally, numerical results are compared to experiments, which lead to a discussion and a conclusion.

\section{Materials}

A one-part rubber toughened epoxy/amine adhesive was chosen for this study. It is employed in the automotive field because of its high deformability and a particular ability to be resistant in crashes. The network is based on a mixture of several epoxy monomers, mainly diglycidyl ether of biphenol (DGEBA) and the hardener is dicyandiamide (DDA). Additives (almost 50\% in mass) like mineral fillers (mainly $\mathrm{Si}$-/Ca-based, $\mathrm{Al} / \mathrm{Mg}$ traces), rubber particles, accelerators and plasticizers also compose the industrial adhesive.

A sheet of approximately $2.5 \mathrm{~mm}$ thickness was prepared. Pasted adhesive is stored in a cartridge. An adequate quantity is heated to $50{ }^{\circ} \mathrm{C}$ for $2 \mathrm{~min}$ to enable it to be more freely moulded. It is then applied along one side of a square region bounded by a Teflon gasket of controlled thickness placed on an aluminium plate pre-coated in releasing wax. A low pressure is applied on the pasted adhesive with a second waxed plate to spread it into the gasket and avoid air being trapped. The adhesive is cured at $180^{\circ} \mathrm{C}$ for $45 \mathrm{~min}$ after a heating at a rate of $10^{\circ} \mathrm{C} / \mathrm{min}$. It is then cooled at ambient temperature. Some adhesive sheets were cut and no voids were found. The sheet is finely abraded to remove the thin skin in contact with the wax during the curing and thickness is calibrated during this step. Sheets are then machined to a dog-bone form using CAM machines (section of $2.5 \times 2.5 \mathrm{~mm}^{2}$ ). Test coupons are kept under vacuum at ambient temperature. The glass transition temperature obtained with this process is close to $95^{\circ} \mathrm{C}$ (value obtained in a TA mDSC 2920 at a heating rate of $10^{\circ} \mathrm{C} / \mathrm{min}$ ).

\section{Experimental observations}

\subsection{Gravimetric experiments}

Three test coupons for each case were aged in demineralised water heated at various temperatures $\left(25,40,60\right.$ and $\left.70^{\circ} \mathrm{C}\right)$. An initial weighing was carried out and subsequently the weight was measured periodically using a Sartorius YDK01 analytical balance. When removed from its aging environment, each specimen was surface wiped dry with a soft tissue. As this removal was short, it was considered that the change in boundary condition did not affect the aging process. The percentage of water in the coupon is plotted as function of the square root of time as shown in Fig. 1. A good repeatability is observed and the measuring error is small enough not to be plotted. A study of the water in which samples were immersed, only revealed the presence of slight trace of filler constituents whose mass is negligible in front of the specimen one. Thus, it is considered there is no leaching.

It can be observed that the initial mass uptake is linear as a function of root time for those temperatures. Obviously the initial absorption rate depends on this temperature and is higher at 70 than at $25^{\circ} \mathrm{C}$. After 40 days $\left(32 \mathrm{~h}^{1 / 2}\right)$ at $25^{\circ} \mathrm{C}$, the plot of mass stopped increasing at a level of uptake of 3.5\%. This level has been confirmed by an immersion of 6 months of one specimen, and can be considered as saturation level. The classical Fickian law applied to a plane sheet of $2.5 \mathrm{~mm}$ thickness [18] gave a time needed to reach saturation of about 50 days (with $D_{20}{ }^{\circ} \mathrm{C}=5.68 \times 10^{-13} \mathrm{~m}^{2} / \mathrm{s}$, a constant corresponding to the initial slope of the mass uptake/

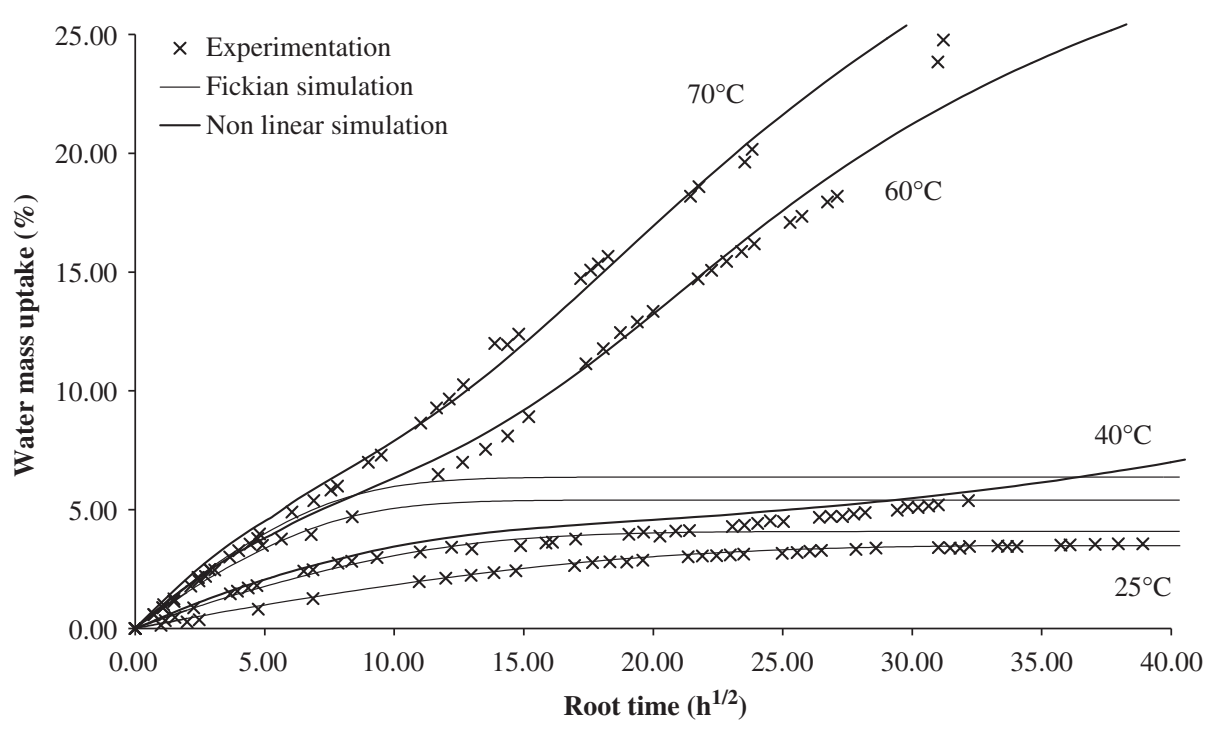

Fig. 1. Experimental and numerical sorption curves at various temperature. 
root time curve at $25^{\circ} \mathrm{C}$ ). In this case, specimens are sectionsquared and diffusion takes place on 4 sides at the same time. Saturation is reached faster than in a simple sheet and a period of 40 days is a reasonable estimation.

After 50 days $\left(35 \mathrm{~h}^{1 / 2}\right.$ ) in water at 40,60 and $70{ }^{\circ} \mathrm{C}$, no saturation was recorded. The plot of mass increased after a pseudo-saturation stage which occurred at about 3.5\%, 4\% and 5\% of mass uptake at, respectively, 40,60 and $70{ }^{\circ} \mathrm{C}$. Nevertheless, saturation may occur at longer times of immersion. As aging is performed very close to the initial $T_{g}$ of the adhesive, the combined effect of water and temperature could be responsible for a change in the chemical structure of the epoxy which could explain these observations. As the adhesive is highly heterogeneous, this increase of the absorption rate could also be attributed to the formation of voids or cavities. These hypotheses will be discussed in the next part of this paper where additional experiments are carried out to explain these observations.

\subsection{Identification of the mechanism responsible for the important} mass uptake observed above $40^{\circ} \mathrm{C}$

DSC analysis was performed on aged adhesive with a TA Instrument 2920, to find if a relation between water content and $T_{g}$ exists. Samples stemmed from the previous cured adhesive sheets were prepared to fit in a crucible and were small enough (diameter: $5 \mathrm{~mm}$, thickness: $0.5 \mathrm{~mm}$ ) to consider their water concentration to be homogeneous during aging. They were immersed in water at $70^{\circ} \mathrm{C}$ for different period and then subjected to DSC. During the heating, water molecules are extracted from the adhesive which is represented on the overall DSC signal by a large endothermal peak. This contribution of water can interfere the determination of the aged adhesive $T_{g}$ during a 'classical' DSC analysis. Modulated DSC analysis allows 'decorrelating' the irreversible contribution of water from the overall signal. The $T_{g}$ of wet adhesive is recorded on the reversible signal during the first heating $\left(0-150{ }^{\circ} \mathrm{C}\right)$ at a rate of $5^{\circ} \mathrm{C} / \mathrm{min}$ $\pm 0.8^{\circ} \mathrm{C} / \mathrm{min}$ (Fig. 2 ).

It can be seen in Fig. 3 that the wet adhesive glass transition temperature decreases rapidly with the water mass uptake. After 24 hours of immersion at $70^{\circ} \mathrm{C}$, which corresponds to an uptake of $5 \%, T_{g}$ value stays around $60{ }^{\circ} \mathrm{C}$. Those observations are attributed to the well known plasticization phenomenon of water on polymers. As the aging temperature is $70^{\circ} \mathrm{C}$, it appears that the adhesive crossed the glass transition during the immersion in water and is in a rubbery state after about $20 \mathrm{~h}$ (mass uptake $2.5-3 \%$ ).

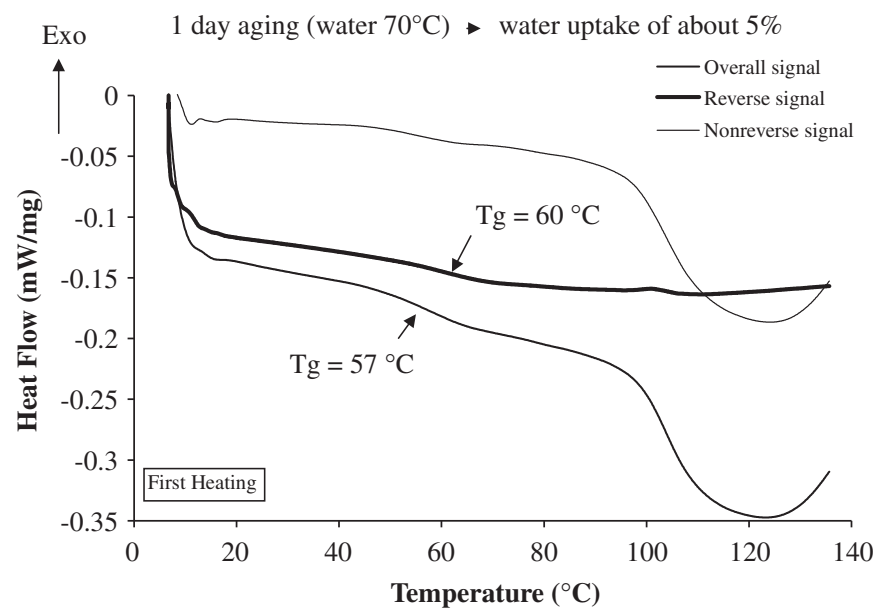

Fig. 2. Example of mDSC signals on an aged coupon of adhesive.

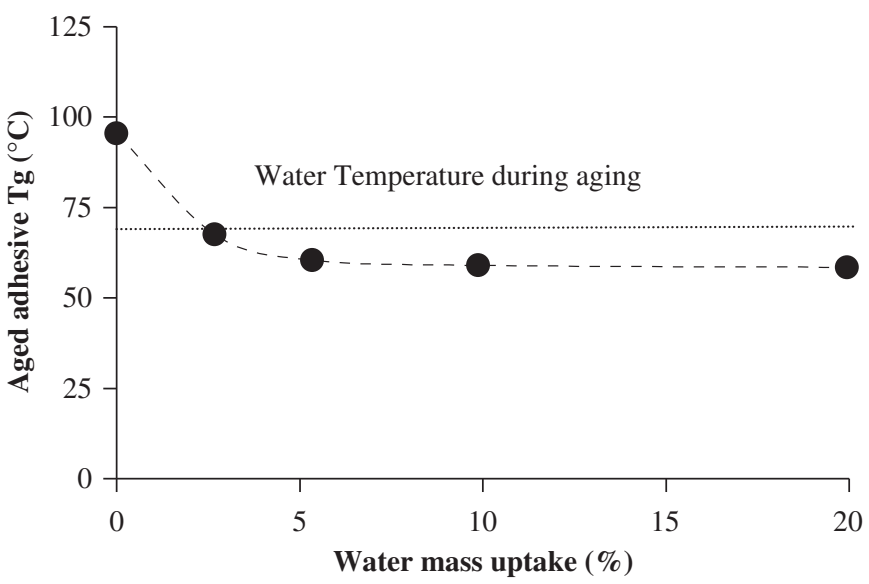

Fig. 3. $T_{g}$ change with water content.

It is known [19] that free volume increases faster with temperature after the cross of glass transition. If the "volumetric approach" used by some authors to explain water absorption [3] is admitted, then solubility should increase proportionally to the generation of free volume (i.e. to the distance $T-T_{g}$ ). In the present study, the aging temperature is constant $\left(70{ }^{\circ} \mathrm{C}\right)$ and the wet adhesive $T_{g}$ reached a constant level $\left(60{ }^{\circ} \mathrm{C}\right)$, which means that the free volume generated should have a finite value. As a consequence, mass uptake should increase progressively towards a saturation level corresponding to a complete filling of the created free volume. But it seems not to be the case for the aging time studied. Moreover, as saturation is reached at $25{ }^{\circ} \mathrm{C}$ after 40 days of immersion in water, one could expect saturation at shorter times at higher temperatures, which is not the case. The "free volume theory" cannot explain completely the gravimetric observations.

Some authors [4] reported that there were no discontinuities in the temperature dependence of solubility or diffusivity at the glass transition temperature of the studied networks, which indicates that the mass uptake process does not depend on the physical state of the adhesive but rather on the interaction between water and hydrophilic sites of the polymer. Considering this "interaction" theory, Tcharkhtchi et al. [4] proposed a formula which is a combination of the Kelley-Bueche polymer-diluent model and the Simha-Boyer rule. It can then be found that, for the studied adhesive of initial $T_{g}$ of $90{ }^{\circ} \mathrm{C}$, the minimal reached $T_{g}$ of $60{ }^{\circ} \mathrm{C}$ corresponds to a mass uptake of about $5 \%$. But as exposed in Fig. 1 the mass uptake increases to higher values, where as the $T_{g}$ of adhesive/water complex stays constant (Fig. 3). This could mean that the adhesive network saturation level is reached at $5 \%$ of mass uptake, but water still ingresses somewhere else, in cavities that appear because of the water diffusion and its related chemical and/or mechanical consequences.

In order to confirm this hypothesis, fracture analyses were performed on aged adhesive. Specimens were immersed in liquid nitrogen for about $2 \mathrm{~min}$ after the aging in water at $70^{\circ} \mathrm{C}$ and broken into two parts. Fracture surfaces of two or three specimen per period were observed in a scanning electron microscope Hitachi TM-1000. It seems that cavities appear near mineral fillers after few hours causing their detachment of the matrix when the specimen is broken (Fig. 4). Their size becomes very important as the exposure increases confirming the previous hypothesis. Those observations are qualitatively repeatable (presence and size of cavities depends on size and quantity of mineral fillers). A statistical analysis on an important number of samples may be useful in order to conclude quantitatively on this phenomenon. 

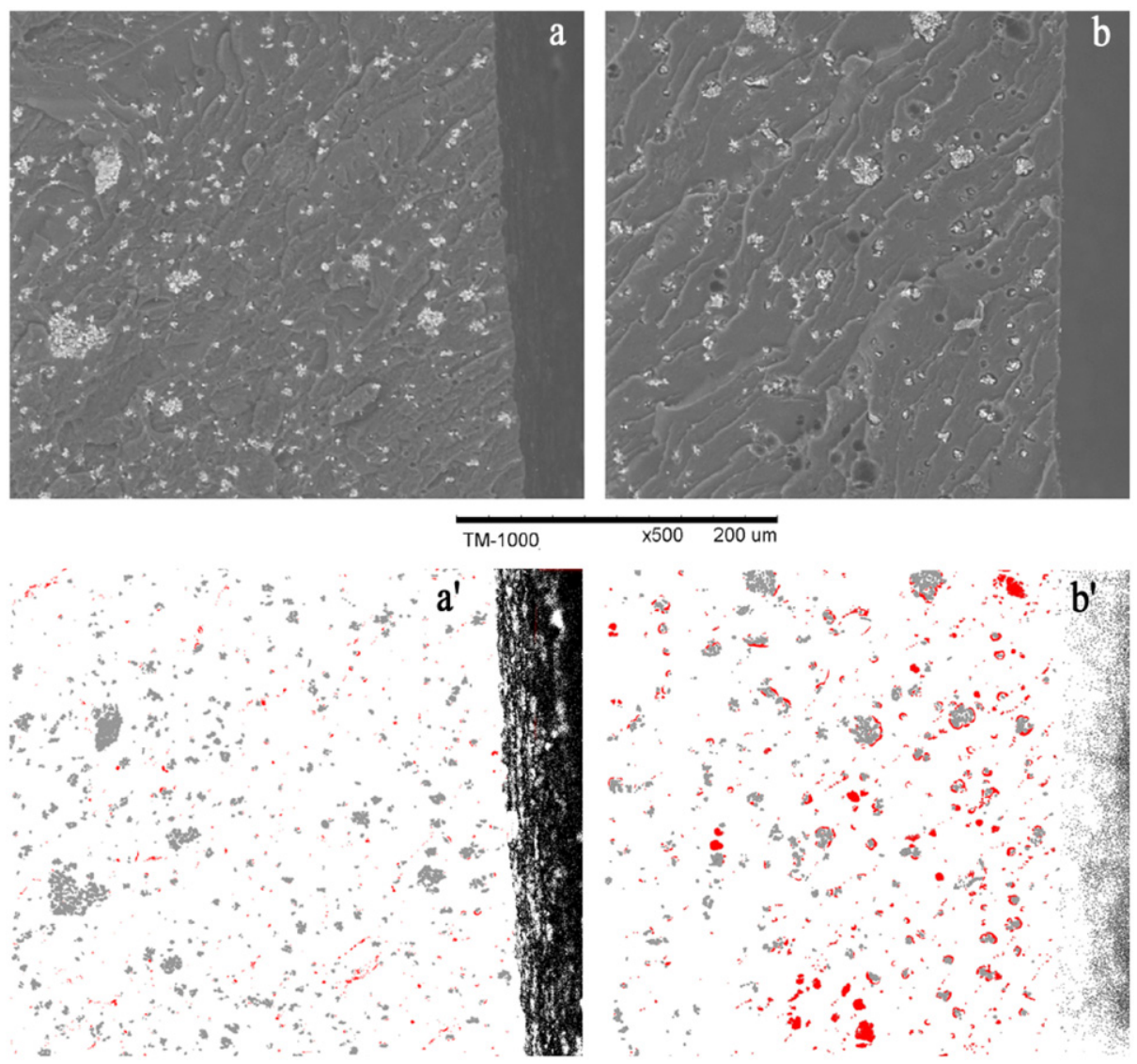

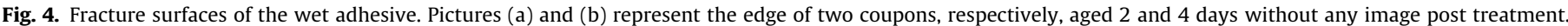

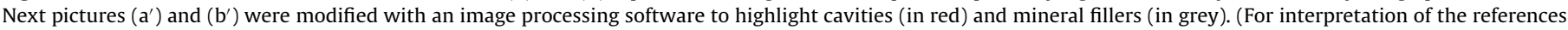
to color in this figure legend, the reader is referred to the web version of this article.)

Possible explanations for the appearance of those cavities are that, from a mechanically point of view, a differential swelling appears between polymer matrix (low stiffness) and fillers (high stiffness) during aging. The interface matrix/filler which could be weakened by the water and/or the temperature is broken by the local state of stress. Some volume is then generated by this fracture. This process can be delayed explaining the growth of cavities:

- A certain time is needed to break the entire interface around the filler (thermo-activated process).

- The matrix viscoelasticity can delayed the generation of volume.

- When the interface is broken, there is a redistribution of stress towards the "healthy" interfaces matrix/filler which have to support an excess of stress and can be broken afterwards.

But, as we highlighted previously, when the matrix of the adhesive is saturated by 'bound' water, $T_{g}$ becomes lower than aging temperature. In the rubbery state, viscoelasticity times needed to recover equilibrium are shorter than in the glassy state. This is all the more disturbing since it is in opposition with the previous assumption. To explain the growth of cavities, it seems that the kinetic of interface degradation is of first importance while the viscoelasticity is negligible. It should be necessary to focus more precisely on this mechanism to conclude.

The presence of water-soluble salts can also lead to osmotic processes and growth of cavities as shown by some authors $[20,21]$. However, in the present case, when specimens are immersed at $70^{\circ} \mathrm{C}$, there is no trace of salts, impurities or other chemical product indicating a leaching in the aging water. But, the hypothesis of osmotic process implies that salts stay in the cavities since there is no leaching and since the initial mass is recovered after drying stage. A kinetic of dissolution (and the subsequent osmotic process) could explain the growth of cavities for such hypothesis.

Formation and growth of cavities is probably caused by a combination of those two processes, but since very few data concerning the precise composition of the adhesive are in possession of the authors, it is not possible to conclude more precisely. This question is still open.

Other experiments came to confirm the previous assumption of the growing cavities. The volume and the mass of specimens were periodically checked during aging at 25,60 and $70{ }^{\circ} \mathrm{C}$ and during a drying stage at $25^{\circ} \mathrm{C}$ under vacuum and silica gel. Volume was determined by recording the mass of coupons in air and in water at room temperature and by applying the relation ( 0 ) born from the law of Archimedes (mass is evaluated with the same balance as in Section 3.1)

$V=\frac{m_{a}}{\left(m_{a} d_{w} / A\left(m_{a}-m_{w}\right)\right)+d_{a}}$

where $m_{a}$ and $m_{w}$ are the masses of an adhesive sample, respectively, in air and in water, $d_{a}$ and $d_{w}$ are the density of air and water at room temperature and $A$ is a constant integer representing the effect of Archimede's force on the weighing device.

The volume expansion as a function of mass uptake seems not to depend a lot on temperature (Fig. 5). The swelling is linear at the beginning of the immersion which allows defining a water expansion coefficient $\alpha^{\text {water }}$. After 6\% of mass uptake, the swelling 

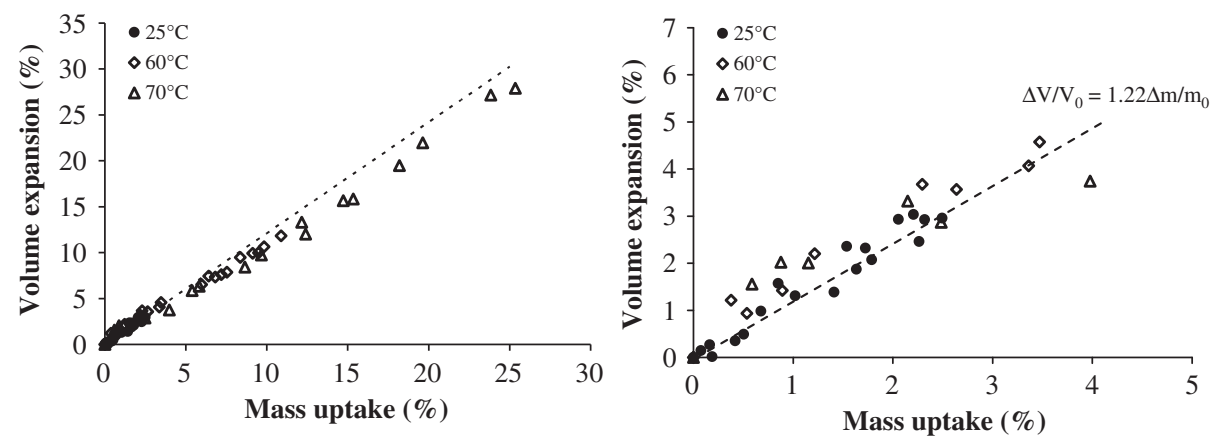

Fig. 5. Volume expansion of the adhesive during aging at various temperatures against mass uptake.

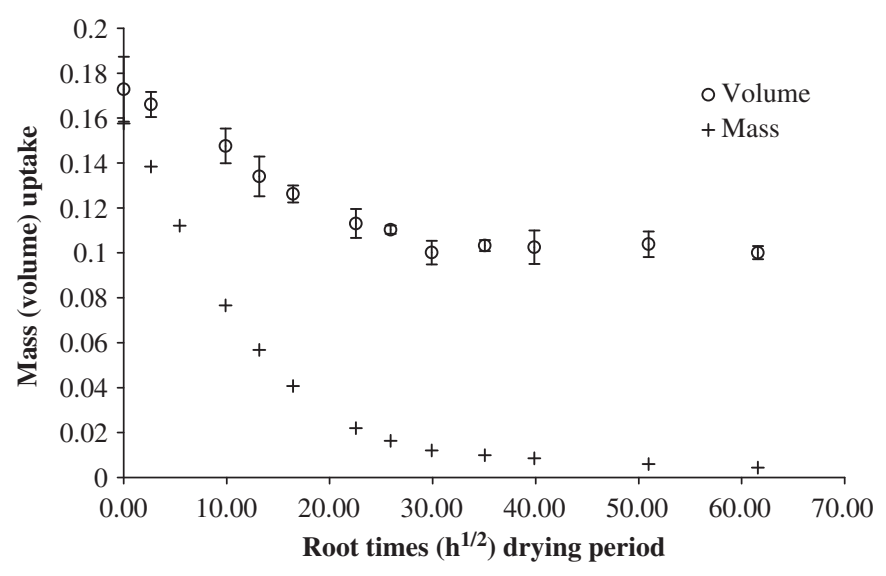

Fig. 6. Evolution of mass and volume of adhesive samples during drying stage at $25{ }^{\circ} \mathrm{C}$ under vacuum.

uptake decreases a little and seems to come back to its initial value.

After a drying stage on previously aged coupons (14 days at $70{ }^{\circ} \mathrm{C}$ ), the final mass is very close to the initial one (Fig. 6) meaning that almost all the water molecules, that ingress into the network have been desorbed. On the contrary, the volume of samples remains very important compared to its initial value. Since there is no leaching, this observation confirms that a chemical reaction at the interface polymer/filler, if it exists, is negligible in front of the swelling effect and/or osmotic process on the cavity development. This cavitation phenomenon is irreversible. As a consequence it seems obvious that the cavities generated during aging in water are responsible for the important mass uptake observed in Fig. 1. All these facts were taking into account to develop a model to simulate the diffusion behaviour of water into the studied structural adhesive.

\section{Modelling diffusion of water}

\subsection{Hypothesis}

To model the diffusion behaviour of this adhesive it has been assumed that the ingression of water into the network was based on a non-linear solubility. Its evolution with the exposure will generate the increase of water diffusion rate and growing of cavities. Consequently the amount of cavity is supposed to increase with time of exposure and this phenomenon is thermoactivated. In order to take this effect into account, it has been chosen to partition the total amount of water that ingresses into the adhesive into two parts to model both diffusion in network and cavity formation: "unbound" water molecules which reside in cavities and "bound" water molecules which are linked to hydrophilic groups and can diffuse into the adhesive matrix from hydrophilic groups to others. That is to say, the "bound" molecules represent the molecules in the Fickian formalism, or the "free" and "bound" water of the Langmuir type diffusion. A slightly modified Fickian law will be used to model the diffusion of the "bound" part.

\subsection{General framework}

Experiments reveal a non-classical diffusion behaviour which looks like a "dual mode". In the literature, those types of behaviour are modelled by non-linear laws (using $D\left(C_{\text {water }}\right)$ ). In this paper, the authors reconsider this type of model in order to link this change of behaviour with the formation of cavities. Thermodynamic formalism is restricting and do not facilitate reading, but it is mandatory if ones want to introduce a coupling between diffusion and mechanics, as it is the case here, since swelling participate in the cavitation and since the latter is responsible of a decrease of mechanical properties. Using a state variable linked to cavities will allow the authors improving the model to considerer coupling between mechanics and diffusion.

The wet adhesive is considered to be a homogeneous nonreacting mixture of polymer and water described in the formal framework of the thermodynamics of irreversible processes with internal variables and generalized normality rule. The water and polymer mass fraction are defined as follows:

$Y_{p}+Y_{e}=\frac{m_{p}}{m}+\frac{m_{e}}{m}=1$

where $Y_{e}$ is the water mass fraction (i.e. mass of water $m_{e}$ upon total mass $m$ of the adhesive/water mixing), $Y_{p}$ the polymer mass fraction (i.e. mass of polymer $m_{p}$ upon total mass of the adhesive/ water mixing).

The second assumption is the separation of the water mass fraction between the "bound" fraction of water $Y_{e}^{b}$ and the "unbound" fraction of water $Y_{e}^{u}$

$Y_{e}=Y_{e}^{b}+Y_{e}^{u}$

System's energy $\Psi$ depends on the global state, precisely on the mass fraction of constituents. It is considered that, for water, $Y_{e}^{b}$ is the only part that can change the system's energy by creating/breaking weak bonds in the hydrophilic sites. As a consequence, $\Psi$ only depends on $Y_{p}$ and $Y_{e}^{b}$. For small changes of these variables, one can always write energy as a simple limited development, for example a bilinear form. Such an expression would led to the Fickian law, that is why the authors extended this development integrating high order terms, here two functions $F\left(Y_{e}^{b}\right)$ and $G\left(Y_{p}\right)$ describing the non-classical behaviour. These functions will have to be evaluated 


$$
\begin{aligned}
\psi\left(Y_{e}^{b}, Y_{p}\right)= & \mu_{e}^{0}\left(Y_{e}^{b}-Y_{e}^{0}\right)+\mu_{p}^{0}\left(Y_{p}-Y_{p}^{0}\right)+\frac{D_{e}}{2}\left(Y_{e}^{b}-Y_{e}^{0}\right)^{2} \\
& +\frac{D_{p}}{2}\left(Y_{p}-Y_{p}^{0}\right)^{2}+d_{e p}\left(Y_{e}^{b}-Y_{e}^{0}\right)\left(Y_{p}-Y_{p}^{0}\right)+F\left(Y_{e}^{b}\right)+G\left(Y_{p}\right)
\end{aligned}
$$

where $\mu_{e}^{0}$ and $\mu_{p}^{0}$ are the chemical potential at reference pressure and temperature for water mass fraction and polymer mass fraction, respectively, $Y_{e}^{0}$ and $Y_{p}^{0}$ are initial water and polymer mass fractions. $D_{e}, D_{p}$ and $d_{e p}$ are coupling parameters linked to the diffusivity of the constituents in the mixture, non-linear functions $F$ and $G$ are user defined and represent the deviation to the non-linearity of the response. The model introduces thermodynamic potentials which results in constitutive laws. The adhesive solubility will be naturally deduced from the expression of chemical potentials. Concerning, the chemical potential of dissolved water (bound water in this case) in the solid adhesive $\mu_{e}$, it derived from the Gibbs free energy

$\mu_{e}=\frac{d \psi}{d Y_{e}^{b}}=\mu_{e}^{0}+D_{e}\left(Y_{e}^{b}-Y_{e}^{0}\right)+d_{e p}\left(Y_{p}-Y_{p}^{0}\right)+f\left(Y_{e}^{b}\right)$ with $f=\frac{d F}{d Y_{e}^{b}}$

and

$\mu_{p}=\frac{d \psi}{d Y_{p}}=\mu_{p}^{0}+D_{p}\left(Y_{p}-Y_{p}^{0}\right)+d_{e p}\left(Y_{e}^{b}-Y_{e}^{0}\right)+g\left(Y_{p}\right)$ with $g=\frac{d G}{d Y_{p}}$

In this case where the diffusion of water occurs in a solid polymer, it can be considered that $\mu_{p}$ is constant and that $D_{p}$ is much smaller than $D_{e}$. It is also decided, in this first approach, not to study the coupling effect between constituents introduce by $d_{e p}$.

The classical Fickian law concerning the dissipation is assumed to be valid

$\overrightarrow{J_{e}}=-k_{\mu} \overrightarrow{\operatorname{grad}}\left(\mu_{e}-\mu_{p}\right)$

where the parameter $k_{\mu}$ will enter the definition of the coefficient of diffusion (Eq. (7)).

Considering Eqs. (1), (2), (4) and (5)

$$
\begin{aligned}
\overrightarrow{J_{e}}= & -k_{\mu}\left(\Delta \overrightarrow{\operatorname{grad}}\left[Y_{e}^{b}-Y_{e}^{0}\right]-\Delta^{\prime} \overrightarrow{\operatorname{grad}}\left[Y_{e}^{u}\right]\right. \\
& \left.-\overrightarrow{\operatorname{grad}}\left[f\left(Y_{e}^{b}\right)-g\left(1-Y_{e}^{b}-Y_{e}^{u}\right)\right]\right)
\end{aligned}
$$

where $\Delta=\left(D_{e}+D_{p}-2 d_{e p}\right)$ and $\Delta^{\prime}=\left(D_{p}-d_{e p}\right)$.

The second Fickian law concerning the mass balance is applied

$\rho \frac{d Y_{e}}{d t}=-\operatorname{div}\left(\overrightarrow{J_{m_{e}}}\right)$

by employing Eqs. (7) and (2), it can be shown

$\frac{d Y_{e}^{b}}{d t}=-\operatorname{div}\left\{\begin{array}{l}-\frac{k_{\mu}}{\rho} \Delta \overrightarrow{\operatorname{grad}}\left[Y_{e}^{b}-Y_{e}^{0}\right]-\frac{k_{\mu}}{\rho} \Delta^{\prime} \overrightarrow{\operatorname{grad}}\left[Y_{e}^{u}\right] \\ -\frac{k_{\mu}}{\rho} \overrightarrow{\operatorname{grad}}\left[f\left(Y_{e}^{b}\right)-g\left(1-Y_{e}^{b}-Y_{e}^{u}\right)\right]\end{array}\right\}-\frac{d Y_{e}^{u}}{d t}$

This first development displays that the evolution of water mass fraction can be separated into three parts. The left part of this expression represents the classical Fickian diffusion with the gradient of "bound" water mass fraction. The central part allows to introduce some non-linearity in the diffusion by choosing functions $f$ and $g$, while the right part, which is the time derivative of the "unbound" water mass fraction that can be consider as a "material sink" term. The gradient of "unbound" water can be neglected in front of the gradient of "bound" water since $\Delta^{\prime}$ is negligible in front of $\Delta\left(d_{e p}\right.$ and $D_{p}$ very small in this study compared with $D_{e}$ ).
Remark. If $f$ and $g$ are null functions then this expression can be obtained

$\Delta=\frac{D \rho}{k_{\mu}}$

where $D$ is the classical linear Fickian coefficient of diffusion of water in the adhesive and $\rho$ its density.

\subsection{Boundary conditions and solubility definition}

It is now necessary to evaluate the evolution of the chemical potential of the water at specimen's edges. It is known that at the interface between two media A and B where species can diffuse, their chemical potentials in $A$ are equal to their chemical potentials in B. For this study where adhesive specimens are immersed in demineralised water, the chemical potential of water at the edges is the chemical potential of liquid water

$\mu_{e}^{0}\left(p^{0}, T\right)+\frac{R T}{M_{m}} \ln a=\mu_{e}^{\text {liquid }}$

where $a$ is the activity of water. Eq. (4) gives the chemical potential of water in the adhesive so obviously at edges. As chemical potentials of water are equal at the solid/liquid interface, the following relation is obtained by assuming the specimen to be completely dry at the beginning of the experiment, thus $Y_{e}^{0}=0$ and $Y_{p}^{0}=1$

$\frac{R T}{M_{m}} \ln a=D_{\text {bord }} Y_{e}^{b}-d_{e p} Y_{e}^{u}+f\left(Y_{e}^{b}\right)$ where $D_{\text {bord }}=D_{e}-d_{e p}$

The previous relation is rewritten in order to define solubility parameters

$Y_{e}^{b}+\frac{1}{D_{\text {bord }}} f\left(Y_{e}^{b}\right)=S_{0}+S^{u} Y_{e}^{u}$ where $S_{0}=\frac{R T}{D_{\text {bord }} M_{m}}$ and $S_{u}=\frac{d_{e p}}{D_{\text {bord }}}$

More precisely the "bound" water mass fraction at edges depends on $S_{0}$, the intrinsic solubility of the adhesive $S$ divided by the volumetric mass $\rho$, and a second term involving the "unbound" water mass fraction and a coefficient without dimension $S^{u}$ which represents the impact of cavitation on the overall solubility. Consequently the evolution of $Y_{e}^{b}$ directly depends on the generation of cavities $\left(Y_{e}^{u}\right)$.

To complete this model, the "material sink" term in Eq. (9) defined to be the time derivative of the "unbound" water mass fraction has to be developed. It obviously depends on the chemical potential but also on the state of stress which can contribute to the opening or closing of cavities and subsequently on the diffusion

$\frac{d Y_{e}^{u}}{d t}=\Phi\left(\mu_{e}, \sigma\right)$

\subsection{Proposition of phenomenological laws to describe the diffusion}

The general framework has been described in the previous section. To apply this phenomenological model to the diffusion of water in the studied adhesive, simplifications and specific mathematical functions were chosen to reproduce experimental observations.

$F$ and $G$ introduced in Eq. (3) are defined

$F\left(Y_{e}^{b}\right)=\beta\left(Y_{e}^{b}+e^{-\delta Y_{e}^{b}}\right), \quad G\left(Y_{p}\right)=$ Cste

The function $F$ has been chosen to introduce some nonlinearity in the initial sorption and to take into account a possible deviation between classical Fickian behaviour and actual sorption behaviour. The parameter $\beta$ controls the initial rate of diffusion, 
while $\delta$ modifies the inflexion of the curve towards the final solubility. The influence of $F$ quickly decreases not to disturb the following sorption generated by the growing cavities (represented by the function $\Phi$ ). It is then supposed that, as $Y_{p}$ do not vary a lot, the function $G$ is constant. As a consequence Eq. (9) becomes

$\frac{d Y_{e}^{b}}{d t}=-\operatorname{div}\left\{-\frac{k_{\mu}}{\rho} \Delta \overrightarrow{\operatorname{grad}}\left[Y_{e}^{b}\right]+\frac{k_{\mu} \beta \delta}{\rho} \overrightarrow{\operatorname{grad}}\left[e^{-\delta Y_{e}^{b}}\right]\right\}-\frac{d Y_{e}^{u}}{d t}$

Then, the equilibrium relation defined in Eq. (13) becomes

$Y_{e}^{b}+\frac{\beta}{D_{b o r d}}\left(1-\delta e^{-\delta Y_{e}^{b}}\right)=S_{0}+S^{u} Y_{e}^{u}$

This expression deduced of the equality of chemical potential at specimen's interfaces constitutes the boundary conditions which will be employed to model the diffusion of water. The amount of "bound" water in the adhesive is first controlled by the diffusion kinetic, but also by the amount of "unbound" water (i.e. cavities) as shown in Eq. (17). To simplify the model, no coupling between mechanics and diffusion are allowed and the function $\Phi$ (which is in relation with the formation and growing of cavities) is not dependent on stress.

To generate sorption curves as seen in Fig. 1, the "unbound" water mass fraction must increase rapidly at the beginning of the immersion in water and progressively tend towards a saturation level, while the "bound" part of water ingresses following a Fickian law. To reproduce this trend, here is the function $\Phi$ that has been proposed

$\frac{d Y_{e}^{u}}{d t}=E_{u}\left(4 C_{u} Y_{e}^{b^{3}}+2 D_{u} Y_{e}^{b}\right) e^{-\left(C_{u} Y_{e}^{b^{4}}+D_{u} Y_{e}^{b^{2}}\right)}$

A more advanced study in micro mechanics should be necessary to validate this law. The value of $D_{u}$ principally influence the initial rate (i.e. the rate of appearance of cavities) of $d Y_{e}^{u} / d t$ as a function of $Y_{e}^{b} . C_{u}$ is responsible of the threshold effect when aging times become important. Parameter $E_{u}$ determines the maximal value of $d Y_{e}^{u} / d t$ (i.e. controls the overall kinetics of cavity appearance).

Finally for this model, nine parameters have to be identified to make calculations: $D, \rho, k_{\mu}, \beta, \delta, C_{u}, D_{u}, E_{u}$ and $S^{u}$.

$R q$ 1: If $\beta=0$ and $E_{u}=0$, the diffusion of water is Fickian.

$R q$ 2: If $E_{u}=0$ and $\beta \neq 0$, the "unbound" part of water will always be zero (i.e. no cavity generation). But the diffusion is nonlinear as expected in Eq. (16).

\subsection{Finite element integration}

A simple two dimensions finite element model is developed with the industrial software ABAQUS ${ }^{\mathrm{TM}}$ to simulate the diffusion of water in our specimens (Fig. 7). From a water diffusion point of view, this 2D numerical model gives similar results compared to a more complex 3D model but it simplifies the integration of the equations presented before. The FE model represents a quarter of a section's specimen with appropriate symmetrical conditions and water boundary conditions.

To simulate the ingression of water into the bulk adhesive, the analytical model is integrated in a user subroutine UMATHT for ABAQUS $^{\mathrm{TM}}$. It allows defining the diffusion law described in this part. $Y_{e}^{u}$ is calculated by integrating $d Y_{e}^{u} / d t$ (see Eq. (18)) and by considering $Y_{e}^{b}$ to vary linearly during each time increment. The solubility which depends on $Y_{e}^{u}$ is also determined in this subroutine during the increment, and affected at each interface nodes. The last term of the transport Eq. (16) is computed in a second user subroutine DFLUX for ABAQUS (Distributed FLUX defines non-uniform distributed flux in a heat transfer or mass

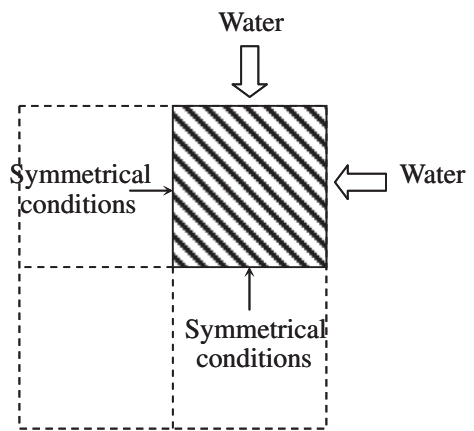

Fig. 7. Simple finite element model for water diffusion study representing a quarter of a section.

diffusion analysis as a function of position, time, temperature, element number, integration point number, etc.), while the equilibrium relation (17) at edge is solved with a last user subroutine DISP for ABAQUS (DISP define the magnitudes of prescribed boundary conditions).

Mechanics and diffusion equations are solved at the same time. In ABAQUS, a coefficient $\alpha^{\prime}$ is needed to link the unidimensional swelling $\left(\varepsilon^{l}\right)$ and the subsequent change of volume (supposed to be homogeneous in this problem) to the mass uptake $\left(Y_{e}\right)$

$\varepsilon^{l}=\alpha^{\prime} Y_{e}$ and $3 \varepsilon^{l} \approx \frac{\Delta V}{V_{0}}$

As a consequence, the constant $\alpha^{\text {water }}$ obtained in Fig. 6, which links water mass uptake $\left(Y_{e}\right)$ and volume expansion $\left(\Delta V / V_{0}\right)$ is included in the model to describe the change in dimension with the mass uptake

$\varepsilon^{l}=\frac{\alpha^{\text {water }}}{3} Y_{e}$

In first approximation, a temperature dependent linear elastic law $(\underline{\underline{\underline{\underline{L}}}})$ is included to describe the mechanical behaviour of the adhesive during the absorption and obtain the stress field

$\underline{\underline{\sigma}}=\underline{\underline{\underline{L}}}\left(\underline{\underline{\varepsilon}}-\underline{\underline{\varepsilon}}^{\text {swelling }}\right)$ with $\underline{\underline{\varepsilon}} \underline{\text { swelling }}=\varepsilon^{\text {swelling }} \underline{\underline{1}}=\frac{1}{3} \frac{\Delta V}{V_{0}} \underline{=}=\alpha^{\text {water }} Y_{e}^{b} \underline{\underline{1}}$

Such description is obviously incomplete since it does not include the water dependence of mechanical properties, but it allows taking into account a volume change (close to the real change) in the diffusion process. The calculation gives the local state of diffusion and stress in the section, but to obtain the overall water mass fraction $Y_{e}$ a post treatment file was developed with PYTHON ${ }^{\mathrm{TM}}$ to collect and sum the amount of "bound" and "unbound" water at each Gauss point for each increment.

\section{Temperature dependent parameters identification}

\subsection{Fickian diffusion of the "bound" water mass fraction}

Preliminary calculations were made for short time exposure. As mentioned above, the diffusion behaviour is Fickian in this condition. In order to simulate this behaviour, $\beta$ and $E_{u}$ were set to zero in the FE model. It has been assumed previously that the "bound" water mass fraction can be predicted by a Fickian law whatever the temperature. With this first analysis both coefficient of diffusion and solubility for $Y_{e}^{b}$ were determined by fitting experimental and numerical curves of water sorption. 
Particular attention was also paid to the Arrhenius existing dependence concerning the coefficient of diffusion and the solubility.

Some attempts were necessary to find the best values for coefficients to fit the mass uptake experimental curves (Fig. 1). Numerical results are good for short time diffusion whatever the temperature. But after 25, 60 and $400 \mathrm{~h}$ at, respectively, 70, 60 and $40{ }^{\circ} \mathrm{C}$, Fickian diffusion does not allow the diffusion behaviour to be correctly described. Fig. 8 displays the Arrhenius plot of $D$ and $S$ as a function of temperature. Concerning the diffusion coefficient, at $70{ }^{\circ} \mathrm{C}$, it is assumed that as the glass transition of the aged adhesive have been crossed, its dependence against temperature change but have not been identified for higher temperature during this study.

As the Fickian diffusion gives good prediction of the mass uptake for short time exposure, the values of $\beta$ and $\delta$ are chosen (respectively, $3 \times 10^{-15}$ and 100) to cancel the non-linear effect they can introduce on this initial sorption. They are also independent on temperature. As a consequence, in Eq. (17), the exponential term can be neglected (order of magnitude of $Y_{e}^{b}: 10^{-2}$, $D_{\text {bord }}: 10^{-9}$ ):

$Y_{e}^{b}=S_{0}+S^{u} Y_{e}^{u}$

\subsection{Non-linear diffusion of the "unbound" water mass fraction}

The next step consists in introducing the function $\Phi$ and finding a satisfying set of parameters $C_{u}, D_{u}, E_{u}$ and $S^{u}$ to predict the sorption behaviour at 40,60 and $70{ }^{\circ} \mathrm{C}$.

Some calculations are made taking into account the Fickian behaviour that has been identified in Section 5.1 as a function of temperature. The better set of parameters is chosen to fit experimental curves (Fig. 1). For example, to obtain an important sorption as it is observed at $70^{\circ} \mathrm{C}$, it is advised to get small values of $C_{u}$ and $D_{u}$ and important values of $E_{u}$ and $S^{u}$ (see physical meaning of parameters in Section 4.4). Parameter's values were plotted as a function of the temperature (Fig. 9). It appears that linear laws were sufficient to predict their evolution up to $70{ }^{\circ} \mathrm{C}$.

Simulation gives good prediction of the diffusion behaviour in adhesive specimen. At $40{ }^{\circ} \mathrm{C}$ we over estimate the water uptake at long time exposure, while at 70 and $60{ }^{\circ} \mathrm{C}$ it is rather at short time immersion. The evolution of diffusion parameters as a function of temperature is linear up to $60{ }^{\circ} \mathrm{C}$ and clearly displays the glass transition of the wet adhesive at this temperature where coefficients suddenly change. At $25^{\circ} \mathrm{C}$ the value of $E_{u}$ is small enough to consider the behaviour to be Fickian.
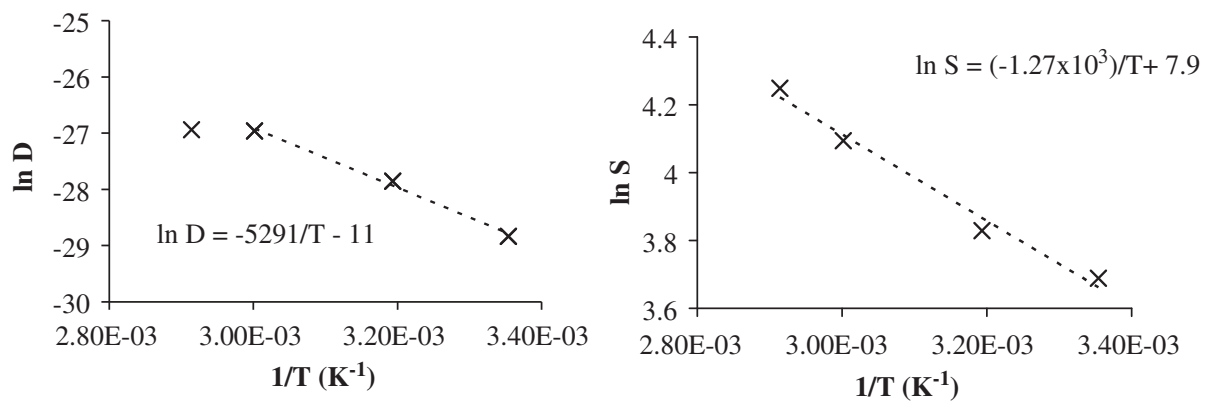

Fig. 8. Arrhenius plot of $D$ and $S$ as a function of temperature.
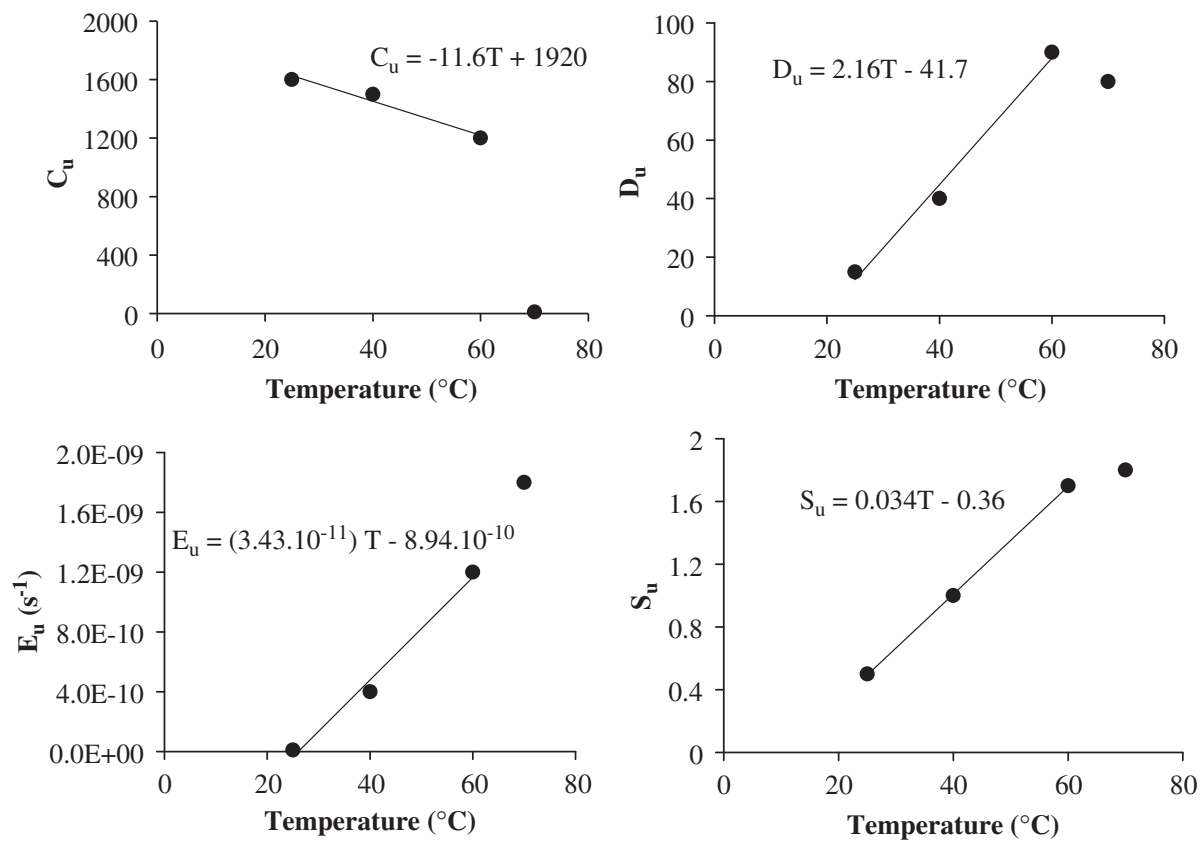

Fig. 9. Evolution of the diffusion parameters as a function of temperature. 

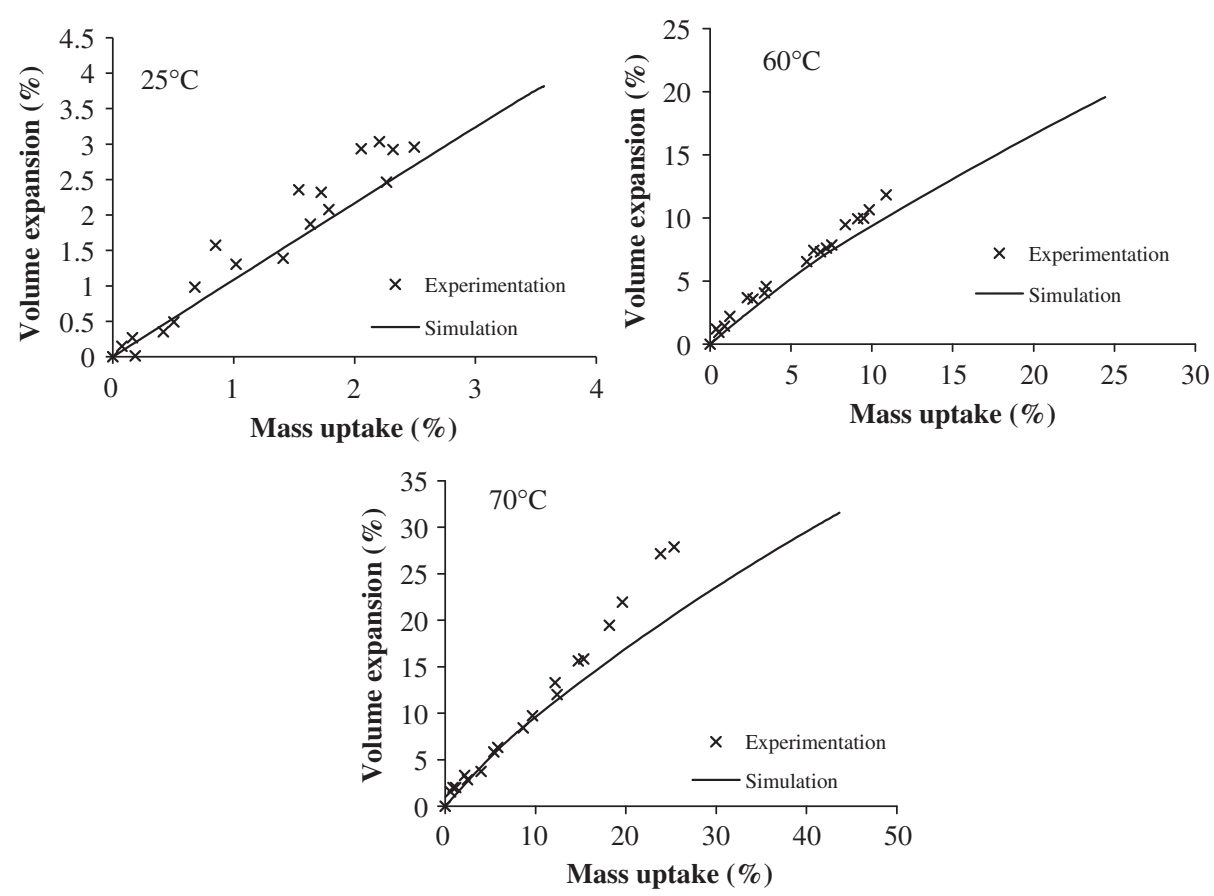

Fig. 10. Experimental and simulated swelling as a function of mass uptake during aging at various temperatures.

\subsection{Limits of the model and possible improvements}

The model gives a reasonable prediction of the swelling at short time diffusion (Fig. 10). But for water uptakes upper than $10 \%$, we underestimate the volumetric expansion. The hypothesis of a linear behaviour of the swelling is not correct. It may be more precise to define two swelling coefficient, one for the "bound" fraction of water, and another one for the "unbound" fraction. Actually, this unbound part of water prevails at long time exposure, and attributing it a more important swelling coefficient should help giving a better description of the swelling behaviour.

Remark. If swelling coefficients are changed, it will be necessary to find another set of parameters to fit the experimental curves.

To validate the model, additional fracture analyses are needed in order to quantify the cavities on the entire surface and compare with the "unbound" water fraction location. In addition, including a complete temperature and water concentration dependent mechanical behaviour law would also give the state of stress in the adhesive during the diffusion. The final objective is to integrate this entire model which takes into account the non-linear diffusion of water and its effect of mechanical properties (gradients of properties), in a finite element description of a bonded assembly to determine the adhesive state of stress before the mechanical loading.

\section{Conclusion}

The study presented covers experimental work and phenomenological modelling of the diffusion of water as a function of temperature in a structural adhesive dedicated to bonding. Experiments have revealed that:

Diffusion behaviour is non-classical for temperature above $40{ }^{\circ} \mathrm{C}$ with important water uptake.

With $5 \%$ uptake, adhesive $T_{g}$ decreases to $60{ }^{\circ} \mathrm{C}$ meaning that the physical state and related diffusion kinetics change during aging in water at 60 and $70{ }^{\circ} \mathrm{C}$.
A cavitation phenomenon occurs during aging and is at the origin of the important water uptake. Swelling caused by ingression of water is the most probable consequence of water diffusion to explain this development of cavities.

A model of diffusion is built on the ground of these observations. Water content is divided into two parts: the "bound" water molecules which diffuse in the adhesive matrix following a Fickian law and the "unbound" water which represents molecules in cavities.

Thanks to a relevant choice of functions and parameters, this model is able to give good prediction of water uptake against root time of immersion at various temperature, even if a deviation concerning the evolution of volume have been recorded for important mass uptake ( $>10 \%$ ).

\section{Model summary}

\subsection{General framework}

Water and polymer mass fraction

$Y_{p}+Y_{e}=\frac{m_{p}}{m}+\frac{m_{e}}{m}=1$

Separation of water mass fraction between "bound" and "unbound" fraction

$Y_{e}=Y_{e}^{b}+Y_{e}^{u}$

Mass balance

$\overrightarrow{J_{m_{e}}}=-k_{\mu}\left(\Delta \overrightarrow{\operatorname{grad}}\left[Y_{e}^{b}-Y_{e}^{0}\right]-\Delta^{\prime} \overrightarrow{\operatorname{grad}}\left[Y_{e}^{u}\right]-\overrightarrow{\operatorname{grad}}\left[f\left(Y_{e}^{b}\right)-g\left(1-Y_{e}^{b}-Y_{e}^{u}\right)\right]\right)$

Transport equation

$\frac{d Y_{e}^{b}}{d t}=-\operatorname{div}\left\{\begin{array}{c}-\frac{k_{\mu}}{\rho} \Delta \overrightarrow{\operatorname{grad}}\left[Y_{e}^{b}-Y_{e}^{0}\right]-\frac{k_{\mu}}{\rho} \Delta^{\prime} \overrightarrow{\operatorname{grad}}\left[Y_{e}^{u}\right] \\ -\frac{k_{\mu}}{\rho} \overrightarrow{\operatorname{grad}}\left[f\left(Y_{e}^{b}\right)-g\left(1-Y_{e}^{b}-Y_{e}^{u}\right)\right]\end{array}\right\}-\frac{d Y_{e}^{u}}{d t}$ 
Table 1

\begin{tabular}{|c|c|c|c|c|c|c|c|c|c|c|c|}
\hline Temperature & $D\left(\mathrm{~m}^{2} / \mathrm{s}\right)$ & $S_{0}$ & $\rho\left(\mathrm{kg} / \mathrm{m}^{3}\right)$ & $k_{\mu}\left(\operatorname{kg~s} / \mathrm{m}^{3}\right)$ & $\beta\left(\mathrm{m}^{2} / \mathrm{s}^{2}\right)$ & $\delta$ & $C_{\mathrm{u}}$ & $D_{u}$ & $E_{u}\left(\mathbf{s}^{-1}\right)$ & $S_{u}$ & $\alpha_{\text {water }}\left(\mathrm{m}^{3} / \mathbf{k g}\right)$ \\
\hline 25 & $3.00 \mathrm{E}-13$ & $3.39 \mathrm{E}-02$ & 1180 & 1 & $3 E-15$ & 100 & 1600 & 15 & $1.00 \mathrm{E}-11$ & 0.5 & 0.403 \\
\hline 40 & $8.00 \mathrm{E}-13$ & $3.90 \mathrm{E}-02$ & 1180 & 1 & $3 E-15$ & 100 & 1500 & 40 & $4.00 \mathrm{E}-10$ & 1 & 0.403 \\
\hline 60 & $1.95 \mathrm{E}-12$ & $5.08 \mathrm{E}-02$ & 1180 & 1 & $3 E-15$ & 100 & 1200 & 90 & $1.20 \mathrm{E}-09$ & 1.7 & 0.403 \\
\hline 70 & $2.00 \mathrm{E}-12$ & $5.93 \mathrm{E}-02$ & 1180 & 1 & $3 E-15$ & 100 & 10 & 80 & $1.80 \mathrm{E}-09$ & 1.8 & 0.403 \\
\hline
\end{tabular}

Equilibrium relation (solubility) at water/adhesive interface

$Y_{e}^{b}+\frac{1}{D_{b o r d}} f\left(Y_{e}^{b}\right)=S_{0}+S^{u} Y_{e}^{u}$

\subsection{Identification}

Transport equation

$\frac{d Y_{e}^{b}}{d t}=-\operatorname{div}\left\{-\frac{k_{\mu}}{\rho} \Delta \overrightarrow{\operatorname{grad}}\left[Y_{e}^{b}\right]+\frac{k_{\mu} \beta \delta}{\rho} \overrightarrow{\operatorname{grad}}\left[e^{-\delta Y_{e}^{b}}\right]\right\}-\frac{d Y_{e}^{u}}{d t}$

Equilibrium relation

$Y_{e}^{b}+\frac{\beta}{D_{b o r d}}\left(1-\delta e^{-\delta Y_{e}^{b}}\right)=S_{0}+S^{u} Y_{e}^{u}$

Rate of water mass fraction entered in cavities

$\frac{d Y_{e}^{u}}{d t}=E_{u}\left(4 C_{u} Y_{e}^{b^{3}}+2 D_{u} Y_{e}^{b}\right) e^{-\left(C_{u} Y_{e}^{b^{4}}+D_{u} Y_{e}^{b^{2}}\right)}$

Parameter's value to obtain results in Fig. 1 are shown in Table 1.

\section{Acknowledgments}

The authors would like to express their appreciation for the financial and technical support of the 'Département de Mécanique et Physique des Matériaux' of the PPRIME Institute. The authors also acknowledge the assistance of Mr. R. Daugreilh for his experimental work on the adhesive, Mr. I. Marr for his help on the development of the model and Mr. JL. Gacougnolle for his wise advice.

\section{References}

[1] Comyn J. Kinetics and mechanism of environmental attack. In: Kinloch AJ, editor. Durability of structural adhesives. Elsevier Applied Science Publishers: 1983. p. 85-131.

[2] Bowditch MR. The durability of adhesive joints in the presence of water. International Journal of Adhesion and Adhesives 1996;16:73-9.
[3] Gupta VB, Drzal LT, Rich MJ. The physical basis of moisture transport in a cured epoxy resin system. Journal of Applied Polymer Science 1985;30: 4467-93.

[4] Tcharkhtchi A, Bronnec PY, Verdu J. Water absorption characteristics of diglycidylether of butane diol-3,5-diethyl-2,4-diaminotoluene networks. Polymer 2000;41:5777-85.

[5] Bellenger V, Verdu J, Morel E. Structure-properties relationships for densely cross-linked epoxide amine systems based on epoxide or amine mixtures .2. Water absorption and diffusion. Journal of Materials Science 1989;24:63-8.

[6] Zhou JM, Lucas JP. Hygrothermal effects of epoxy resin. Part I: the nature of water in epoxy. Polymer 1999;40:5505-12.

[7] Adamson MJ. Thermal expansion and swelling of cured epoxy resin used in graphite/epoxy composite materials. Journal of Materials Science 1980;15: $1736-45$.

[8] Xiao GZ, Delamar M, Shanahan MER. Irreversible interactions between water and DGEBA/DDA epoxy resin during hydrothermal aging. Journal of Applied Polymer Science 1997;65:449-58.

[9] Deneve B, Shanahan MER. Water-absorption by an epoxy resin and its effect on the mechanical properties and infrared spectra. Polymer 1993;34: 5099-105.

[10] Apicella A, Nicolais L, Astarita G, Drioli E. Effect of thermal history on water sorption, elastic properties and the glass-transition of epoxy resins. Polymer 1979;20:1143-8.

[11] Diamant Y, Marom G, Broutman LJ. The effect of network structure on moisture absorption of epoxy resins. Journal of Applied Polymer Science 1981:26:3015-25.

[12] Glaskova TI, Guedes RM, Morais JJ, Aniskevich AN. A comparative analysis of moisture transport models as applied to an epoxy binder. Mechanics of Composite Materials 2007:43:377-88.

[13] Loh WK, Crocombe AD, Wahab MMA, Ashcroft IA. Modelling anomalous moisture uptake, swelling and thermal characteristics of a rubber toughened epoxy adhesive. International Journal of Adhesion and Adhesives 2005;25: $1-12$.

[14] Popineau S, Rondeau-Mouro C, Sulpice-Gaillet C, Shanahan MER. Free/bound water absorption in an epoxy adhesive. Polymer 2005;46:10733-40.

[15] Weitsman Y. Diffusion with time-varying diffusivity, with application to moisture-sorption in composites. Journal of Composite Materials 1976;10:193-204.

[16] Fujita H. Diffusion in polymer-diluent systems. Advanced Polymer Science 1961;3:1-41.

[17] Zhou JM, Lucas JP. Hygrothermal effects of epoxy resin. Part II: variations of glass transition temperature. Polymer 1999;40:5513-22.

[18] Crank J. The mathematics of diffusion. 2nd edition. Oxford Univesity Press; 1975.

[19] Kovacs AJ. Transition vitreuse dans les polymères amorphes. Etude phénoménologique. Fortschritte der Hochpolymeren-Forschung 1964;3: 394-507.

[20] Ivanova KI, Pethrick RA, Affrossman S. Hygrothermal aging of rubbermodified and mineral-filled dicyandiamide-cured DGEBA epoxy resin. II. Dynamic mechanical thermal analysis. Journal of Applied Polymer Science 2001;82:3477-85

[21] Boinard P, Banks WM, Pethrick RA. Changes in the dielectric relaxations of water in epoxy resin as a function of the extent of water ingress in carbon fibre composites. Polymer 2005;46:2218-29. 